http://jmscr.igmpublication.org/home/

ISSN (e)-2347-176x ISSN (p) 2455-0450

crossref DOI: https://dx.doi.org/10.18535/jmscr/v7i8.130

Journal Of Medical Science And Clinical Research

IGM Publication

An Official Publication of IGM Publication

\title{
Laparoscopic surgery in a patient with dilated cardiomyopathy with implanted device -anesthesia considerations Anaesthesia for laparoscopy surgery with implanted device in DCM
}

\author{
Author \\ Dr Deepali Rahate Gomase, MBBS, DNB (Anaesthesia) \\ Senior Consultant, Dept of Anaesthesiology, Ganga Care Hospital, Nagpur \\ 253, Near KRIMS Hospital, Ramdaspeth, Nagpur, India
}

\begin{abstract}
Introduction: Post-partum cardiomyopathy is one of the form of DCM which can occurs from the third trimester of pregnancy till the first 5 months after delivery ${ }^{(I)}$. In dilated cardiomyopathy cardiac reserve is reduced and is the common cause of cardiac failure. Many patients have implanted cardiac device so as to improve survival rate. In United States more than 5, 00,000 patients have pacemakers and each year nearly 1, 15,000 new devices are implanted ${ }^{(2)}$. Understanding the pathophysiology of cardiomyopathy, the implanted device and its anaesthetic implication is important in the management of these cases. The preoperative management involves not only maintaining hemodynamics but also care of such implanted device.

Keywords: Dilated cardiomyopathy, Anesthesia, laparoscopy, defibrillator.
\end{abstract}

\section{Introduction}

Laparoscopic surgeries are popular now a days and anaesthesiologist need to be vigilant throughout the surgery because of effects of pneumoperitoneum. If heart disease patient posted for laparoscopic surgery then that increases the rate of mortality and morbidity. Idiopathic dilated cardiomyopathy is a primary myocardial disease of unknown etiology characterized by left ventricular or biventricular dilation and impaired contractility. We reported a case of patient posted for laparoscopic salphingectomy and excision of ovarian dermoid cyst, patient was a known case of dilated cardiomyopathy with implanted CRTD (cardiac resynchronization therapy defibrillator)

\section{Case Report}

A 38 yrs old female was posted for laparoscopic bilateral salphigectomy and excision of left ovarian demoid cyst. She was known case of dilated cardiomyopathy with EF $30 \%$ with CRTD (Cardiac Resynchronisation therapy defibrillatorpermanent pacemaker) implanted a year back. She was having systemic hypertension along with diabetes mellitus since two years. She was also anaemic. Patient gave history of first normal delivery. At the time of second delivery nearly 7 yrs back she was kept in ICCU after LSCS for cardiac failure and was diagnosed to have dilated cardiomyopathy .CRTD was implanted one year prior. On examination patient gave history of breathlessness on slight exertion, Echo showing EF $30 \%$, pacemaker in situ, mildly dilated LA and 
grade 1 diastolic dysfunction. Her chest was clear, all blood investigations except Hemoglibin (9 gm $\%)$ were within normal limits. On preanaesthetic examination her heart rate was $72 / \mathrm{min}$ and regular. The blood pressure was $110 / 70$ with normal respiratory rate. Preoperative evaluation from cardiologist done including the checking of implanted pacemaker. High risk consent obtained from patient and relatives, emergency drugs and ICU was kept ready. After securing venous lines with $18 \mathrm{~g}$ and $20 \mathrm{~g}$ intracath, an arterial line was put for minute to minute pressure monitoring under local anesthesia. Patient was premedicated with IV pantocid, IV midazolam and inj fentanyl $100 \mathrm{mcg}$. She was induced with etomidate and paralyzed with atracurium. Lignocaine $60 \mathrm{mg}$ given to blunt intubation response. Intubated with ETT no 7, pt was put on ventilator and maintained with O2, Air and sevoflorane. IV paracetamol 1 gm given intraoperatively. Patient hemodynamically remained stable with heart rate between 70-80/min and Blood pressure ranging between 120-130 mmHg. Procedure took nearly 50 minutes after which patient was reversed with myopyrolate and extubated. IV fluids given cautiously, nearly $250 \mathrm{ml}$ of Ringer lactate with $100 \mathrm{ml}$ Paracetamol given. Patient remained stable postoperatively and discharged on $3^{\text {rd }}$ day.

Discussion: Dilated cardiomyopathy is defined by presence of shortening of fractional myocardial less than 25\% (>2SD) and/or ejection fraction less than 45\% (>2SD) and Left Ventricular End Diastolic Diameter (LVEDD) greater than $117 \%$ excluding any known cause of myocardial disease $^{(3)}$. Most of these cases are idiopathic, however in our case it seemed to be postpartum. The known causes are ischemic, valve dysfunction and post viral infection. DCM can also be found in association with sickle cell disease, muscular dystrophy, excess alcohol, hypothyroidism and some chemotherapy agents or during peripartum period $^{(4)}$. Preoperative history in the form of implanted device should be taken properly including the indications for pacemaker, symptoms at the time of implantation, any reappearance of symptoms and the type of pacemaker used. Investigations include all routine investigation with special attention on hemoglobin, potassium and magnesium levels which need to be corrected prior to surgery. In dilated cardiomyopathy goals of anesthesia management should include avoidance of further myocardial depression, maintenance of normovolemia, avoid ventricular afterload and avoidance of sudden hypotension. References are available of doing laparoscopic surgery under regional anesthesia ${ }^{(5,6)}$. We preferred general anesthesia so as to avoid sudden hypotension and to maintain hemodynamics throughout the surgery. Laparoscopic surgery causes pneumoperitoneum which leads to severe hemodynamic changes during insufflations. Arrhythmias like tachycardia and atrial fibrillation are commonly associated with DCM and further aggravated by pneumoperitoneum ${ }^{(7)}$. Previously cardiac disease was considered as contraindication for laparoscopic surgery but considering postoperative benefits it is no longer a contraindication for high risk cases. Low flow insufflations should be considered in such cases. Etomidate, narcotics have minimal cardiac effects and can be safely used. But myoclonic movements of etomidate should be kept in mind. Muscle paralysis can be provided by nondepolarising muscle relaxants, in our case we used atracurium. Fasciculations caused by scoline may interfere with pacemaker activity. Inotropic support if required then dopamine is the drug of choice as it has positive inotropic, chronotropic effects along with vasoconstriction. Our patient was having CRTD, it has been observed that resynchronization therapy causes increase in $\mathrm{EF}$ (LVEF increased from $24+/-9 \%$ to $34+/-11 \%$ ) and thus improves survival rate. Biventricular pacing resulted in improvement of symptoms and quality of life. It also helps to improves 6-minute walking distance test. These effects were observed at 3 months after implantation and were maintained at 6-month follow-up ${ }^{(8)}$. Anesthetist should be aware of implanted device and device related 
complications and management. It is important to determine whether a patient is pacemakerdependent and in case of doubt to assume that they are. Device should be checked preoperatively including the battery status. Hypoxia, hypercapnia, metabolic disturbance, electrolyte disturbance and some drugs may affect the threshold of defibrillator so need to be avoided ${ }^{(9)}$. Electricomechanical interference (EMI) may occur due to cautery(10) and peripheral nerve stimulator. So it is advisable to use bipolar cautery, although EMI can still occur. Even shivering may interfere and can cause rapid pacing. In patients with an ICD, electrocautery interference may be detected incorrectly as VT or $\mathrm{VF}$, resulting in delivery of a shock ${ }^{(10)}$. So it is advisable to reprogramme ICD to monitor mode during surgery by application of magnet. But risk is involved in routine use of magnet as switching to asynchronous pacing may trigger ventricular tachyarrythmias. So use of magnet is not advisable. External defibrillator always should be kept available. If at all external defibrillator needed it should be placed at least $10-15 \mathrm{~cm}$ from the device and the device should be checked after the procedure. In our case our cardiologist checked the ICD but did not prefer to change the mode, we used harmonic cautery so there was no EMI. It is the common cardiomyopathy and considered as third common cause of CHF and most common indication for heart transplantation $^{(1)}$. Heart transplantation is another choice for such patients but because of limited donor supply, lack of facilities and high cost it is less popular.

\section{Conclusion}

Patients with implanted cardiac devices are not so rare now a days. We should always have knowledge regarding the implanted devices, electromagnetic inference. Meticulous preoperative history, Proper intra and post operative monitoring and getting ready for the complications helps smooth conduct of anesthesia and decreases the morbidity and mortality.

\section{References}

1. Rajiv Juneja, Prajeesh M Nambiar, Cardiomyopathies and anesthesia, Indian journal of anaesthesiology REVIEW ARTICLE, Year : 2017 | Volume : 61 | Issue : 9 | Page : 728-735

2. Shivani Rastogi, MD, Sanjay Goel, MD, Deepak K Tempe, MD, Sanjula Virmani, DA, DNB Department of Anaesthesiology and Intensive Care, GB Pant, Anaesthetic Management of Patients with Cardiac Pacemakers and Defibrillators for Noncardiac Surgery, Annals of Cardiac Anaesthesia 2005; 8: 21-32

3. Wood WL, Kuczkowski KM, Beal BR. Anesthetic considerations for cesarean section in the parturient with familial cardiomyopathy. Acta Anaesthesiol Belg. 2008;59:87-9.

4. Haramritpal Kaur, ${ }^{1}$ Ranjana Khetarpal, ${ }^{2}$ and Shobha $\quad$ Aggarwal $^{3} \quad$ Dilated Cardiomyopathy: An Anaesthetic Challenge, J Clin Diagn Res. 2013 Jun; 7(6): 1174-1176.

5. Ravi Raj, Mritunjay Kumar, and Meenu Batra. Anesthetic management of a case of dilated cardiomyopathy for emergency appendectomy, Anesth Essays Res. 2014 Jan-Apr; 8(1): 105-107

6. Gramatica L, Brasesco OE, Mercado Luna A, et al. Laparoscopic cholecystectomy performed under regional anesthesia in patients with chronic obstructive pulmonary disease. Surg Endosc 2002; $16: 472-5$

7. Bickel A, Marinovski M, Shturman A, Roguin N, Waksman I, Eitan A. Filtered signal-averaged P-wave duration during Pneumoperitoneum in patients undergoing laparoscopic cholecystectomy: a reflection of pathophysiological cardiac changes. Surg Endosc.2008;22:221-227.

8. Molhoek SGBax JJvan Erven LBootsma MBoersma ESteendijk Pvan der Wall EE Schalij MJ.Am J Cardiol. 2002 Aug 
15;90(4):379-83. Effectiveness of resynchronization therapy in patients with end-stage heart failure.

9. Stokes, KB and Kay, GN. Artificial electrical cardiac stimulation. in: KA Ellenbogen, GN Kay, BL Wilkoff (Eds.) Clinical Cardiac Pacing and Defibrillation. W.B. Saunders, Philadelphia; 2000: 17-52 10. Senthuran S, Toff WD, Vuylsteke A, Solesburry PM, Menon DK. Implantable cardiac pacemaker and defibrillators in anaesthetic practice- Editorial III. Br J Anaesth. 2002;88:627-31. 